\title{
Indicators of attitude shift from role playing
}

\author{
ALLEN J. SCHUH \\ California State University, Hayward, California 94542 \\ and \\ YING-PAR YOUNG \\ General Motors, Fremont, California 94537
}

\begin{abstract}
Male business students $(\mathrm{N}=296)$ participated in three role-playing experiments. Experiment 2 demonstrated that cognitive change can result from role playing under conditions where the supervisor who is giving the assignment to a subordinate actually believes in the goals of the program $(p<.05)$. Experiment 3 indicated a behavioral change. Participants had a significantly $(p<.05)$ higher tendency than controls to evaluate a female job applicant as acceptable for employment in a supervisory position.
\end{abstract}

This paper reports on the effectiveness of role-playing exercises in changing the attitudes of male business students toward hiring women for a management trainee position.

\section{EXPERIMENT 1}

\begin{abstract}
Method
Participants were male business students $(\mathrm{N}=131)$ drawn from several undergraduate management courses in the School of Business and Economics at California State University. The role-playing exercise was conducted along the lines suggested by Maier, Solem, and Maier (1975). Each person was randomly assigned to one of four roles: personnel manager, recruiter, observer, or control. The personnel managers and recruiters were paired off randomly. Slightly more participants were put in the control group than would have been expected based on pure randomization. The group of observers was raided for this purpose. The personnel manager's role was to assign a $20 \%$ female hiring quota to the recruiter for a management trainee program. The exercise had been used for several years by the first author to train managers and employment interviewers. The exercise lasted $12 \mathrm{~min}$ and was followed by a 5-min debriefing by the observer. Participants were then allowed $5 \mathrm{~min}$ to complete a 25 -item questionnaire on the topic of women in business. The authors' major interest was in the final overall rating. Overall ratings were indicated on a 5-point scale ranging from "I approve of women in managerial positions," to "I totally disapprove of women in managerial positions."
\end{abstract}

\section{Results}

A variance analysis (Winer, 1962) was conducted on the overall rating for the groups: controls $(\mathrm{N}=52)$, personnel managers $(\mathrm{N}=32)$, recruiters $(\mathrm{N}=32)$, and observers $(\mathrm{N}=15)$. There was no difference $[\mathrm{F}(3,130)=.41]$ between any group participating in the training and the control group on the overall rating.

Reprint requests should be sent to the first author, Department of Management Sciences, California State University, Hayward, California 94542.
This victory for the null hypothesis suggests that role playing is not inherently persuasive even though the stakes for compliance are low. The fact that the roleplaying participants did not provide more generous ratings than controls on an overall attitude scale regarding women in business suggests that the demand characteristics are low in this setting. Minor manipulations in the setting that would relate to a difference in overall attitude might be a real effect rather than an experimental artifact. The exercise was revised slightly and we tried again.

\section{EXPERIMENT 2}

\section{Method}

The experiment was conducted along the same lines as Experiment 1 with the following exceptions: (1) The content of the role-playing case was changed to reflect only favorable or neutral information about women in business; (2) a pretest of the participants' cognitions was conducted with the questionnaire; and (3) half of the groups received instruction on Title VII of the Civil Rights Act and other relevant federal and state legislation. Unknown to the participants, their opinion ratings were used to assign them to roles. Those who had the most favorable cognitions toward women in business were assigned the roles of personnel managers. Those with less favorable cognitions were assigned to roles of recruiters or observers.

\section{Results}

Of the recruiters who received the lecture, 8 of the 13 changed to a more favorable stand on the posttest with the questionnaire. Five of the 14 recruiters who received no lecture also changed to a more favorable stand. The change rates for the two groups were not significantly different $\left[\chi^{2}(1)=.91\right]$. A McNemar test (Siegel, 1956) for the change rate for the two recruiter groups combined was significant $(\mathrm{p}<.05)$.

Experiment 2 showed that a role-playing setting can produce significant cognitive change if the personnel 
managers are selected for their roles because they indicate favorable cognitions toward women in management on the pretest. The reactive effects of the pretesting are not known. Whether the change was only a regression effect is also not known. It is known that the lecture by an authority figure on legal aspects of selection had no effect. Thus, there is at least one more victory for the null hypothesis on the effects of demand characteristics in this setting.

The third experiment was designed to include a behavioral indication of attitude change. Participants were required to evaluate the suitability of a female job applicant for a managerial position beyond their role playing.

\section{EXPERIMENT 3}

\section{Method}

The content of the role playing was the same as in Experiment 2. The role playing was conducted by the procedures outlined in Experiment 1 . The experimental group $(\mathrm{N}=45)$ role played, was given the questionnaire, and then heard the interview of a female job applicant and rated her on acceptability for employment. The control group $(\mathrm{N}=39)$ was given the questionnaire, then heard the interview and rated the applicant.

The job applicant was a graduating senior majoring in personnel and industrial relations. The interview consisted of a 20-min discussion of past work history and education. The applicant reported her intention to seek a supervisory position in personnel upon graduation. She had relevant experience, had been a good student, and was somewhat older than other seniors. The authors believed she was eminently qualified.

Participants were provided with a criterion statement for the position of Personnel Supervisor. They were also provided with a rating scale on which they were required to indicate their decision after the interview. The decision was a simple pass-fail. The rater indicated either that the applicant looked promising on information obtained to that point and the decision would be to continue further with the employment procedure, or the decision would be to terminate the employment consideration. These materials and procedures had been extensively pretested in other research (Schuh, 1973).

\section{Results}

Only the recruiters $(\mathrm{N}=15)$ were the target of the attitude change evaluation. The recruiters did not differ from controls $(\mathrm{N}=39)$ on the questionnaire $[\mathrm{F}(1,52)=2.23]$.

On the employment decision, the recruiters did differ from the controls $[F(1,52)=5.60, \mathrm{p}<.05]$.
Eta squared was .10. In the experimental group, 93\%, as compared to $61 \%$ of controls, indicated they would go further with the applicant.

\section{DISCUSSION}

Unfortunately, one can draw different conclusions about role-playing effectiveness depending upon which component of the latent attitude one believes more accurately reflects the true state. Experiment $3 \mathrm{might}$ indicate that the behavioral tendency toward increased acceptance of women into management is there because of role playing, and the cognitive indication will now follow the behavioral tendency to bring the overall attitude into balance with the behavior.

The only time cognitive shift was demonstrated was when the recruiters and personnel managers were preselected for their roles. One interpretation of this result might be that a personnel manager who possesses favorable cognitions presents a believable role for the recruiter to emulate. Other manipulations of the setting failed to produce attitude change. The authors believe that Experiment 2 has shown a promising lead to follow in further research.

There are some weaknesses in Experiment 2 that were pointed out earlier. All experiments have some weaknesses. The important outcome of Experiment 2 was the finding that recruiters can be persuaded if the personnel manager is sympathetic to the program. Maybe the subordinates were sensitive to the manager's sincerity and that gave the whole setting credibility (cf. Zimbardo \& Ebbesen, 1970).

The results suggest that supervisors be screened for attitudes favorable to affirmative action, and those with more positive attitudes should be viewed more favorably during times of reward distribution.

In our professional judgment, the key to an affirmative action program's effectiveness is the degree to which the manager assigning recruiting responsibilities believes what he or she is saying.

\section{REFERENCES}

MAIER, N. R. F., Solem, A. R., \& MAIER, A. A. The roleplay technique. La Jolla, Calif: University Associates, 1975.

Schur, A. J. Effects of interview rating form content and rater experience on the evaluation of a job applicant. Personnel Psychology, 1973, 26, 251-260.

SIEgEL, S. Nonparametric statistics for the behavioral sciences. New York: McGraw-Hill, 1956.

WINER, B. J. Statistical principles in experimental design. New York: McGraw-Hill, 1962.

Zimbardo, P., \& EBBEsen, E. B. Influencing attitudes and changing behavior. Reading, Mass: Addison-Wesley, 1970.

(Received for publication January 20, 1978.) 